\title{
An integrated approach in developing flood vulnerability index of India using spatial multi-criteria evaluation technique
}

\author{
K. H. V. Durga Rao*, Shravya Alladi and Amanpreet Singh \\ Disaster Management Support Division, National Remote Sensing Centre, Indian Space Research Organisation, Balanagar, \\ Hyderabad 500 037, India
}

In recent years, flash floods took place in various parts of the country that are not under floodplains due to high rainfall events, causing damage to rail, road and urban infrastructure. There is a need to develop a flood vulnerable index map of the country for precautionary measures in such vulnerable areas. Developing flood vulnerability index (FVI) at country level in India is a multifaceted job due to huge variations in topographic, meteorological and hydrological conditions over space and time. The paper focuses on developing a scientific approach in preparing FVI map of the country in a spatial decision support system environment by using space-based inputs, topographic data and long-term meteorological data. Probable maximum precipitation (PMP) and high rainfall frequency were computed using 100 years daily rainfall data of the country. Runoff potential of the country was prepared using high resolution landuse, soils, and digital elevation model grids. Probable maximum run-off was further computed at national level using PMP and run-off potential grids. Morphometric analysis was done using topographic and drainage information. All these layers were normalized and integrated in SDSS environment to compute the flood vulnerability index of the country. Suitable weights were given for all layers using the knowledge base reviewed across the globe. Sensitivity analysis and validation were done using the previous flood incidents.

Keywords: Flood vulnerability index, morphometric analysis, probable maximum precipitation, probable maximum run-off, run-off potential, spatial decision support system.

FLOODS are one of major causes of loss of life and property and have an adverse effect on the economy across the globe. Due to major floods that have occurred in recent years in many parts of the globe, local, national, and international authorities have shown an increasing awareness of flood hazard ${ }^{1}$. Research was carried out on providing knowledge for preparing public-based flood mapping and estimating flood risks in growing urban

*For correspondence. (e-mail: khvdurgarao@yahoo.com) areas using integrated analytical hierarchy process and geographic information system tools ${ }^{2}$. Coastal city flood vulnerability indexing based on exposure, susceptibility and resilience to coastal flooding was also addressed by testing the approach in nine cities around the world and along the coast ${ }^{3}$. Researchers have compared the role of parametric and modelling approaches in assessing the flood vulnerability mapping ${ }^{4}$. In another paper, the impact of climate change like flooding and heat on rail infrastructure is described by examining the influence of various meteorological parameters ${ }^{5}$. India is one of the worst flood affected countries in the world; the damage caused by floods in India is immense. In recent years, Indian rail, road and urban infrastructure are exposed to flooding, causing immense damage to property and life. The recent flood in the Machak River, Madhya Pradesh, India and wash out of the road bridge between Goa and Mumbai are a distinctive paradigm of floods that killed number of passengers besides causing incredible damage to rail and road infrastructure and to surrounding villages. This shows the vulnerability of bridges/culverts to flash floods in the country. The recent Chennai and Srinagar floods demonstrate the vulnerability of urban infrastructure to flooding. Interestingly, many of these areas are not in the main floodplains of the countries, but the incidents took place due to extreme rainfall conditions.

Typically rail or road bridges are designed for a 100 year service life. However, with the increase in frequency of extreme events, the probability of failure increases, resulting in a reduction in expected design life. Climate change will not have a huge impact on the infrastructure as the effect due to short-term impact loads are built in the safety factors in the design process ${ }^{6}$. However, extreme natural disasters will have an impact on the vulnerability as the infrastructure may not be designed for such a long-term intense event.

The concept of using modern techniques like remote sensing and geographical information systems (GIS) in flood modelling studies is comparatively new. Flood vulnerability index (FVI) is defined as the extent of damage, which can be expected under certain conditions of exposure, susceptibility and resilience. FVI is a powerful tool for policy and decision-makers to prioritize investments 
and makes the decision-making process more transparent. FVI can provide vital information to protect infrastructure by suitable damage prevention measures. India being a tropical country, developing the FVI of the country is a multifaceted job due to huge variations in morphometric, topographic, meteorological and hydrological conditions over space and time.

Flood vulnerability indices and their frameworks developed by various countries like USA, Japan, Europe, etc. have been examined thoroughly. Considering various factors and constraints, it is proposed to develop the FVI of the country in spatial decision support system environment with the amalgamation of space-based inputs, topographic data, morphometric data, long-term meteorological data and hydrological models. The system provides valuable spatial information on the vulnerability of rail, road and urban infrastructure to flooding.

\section{Methods and approaches}

The term 'risk' in relation to flood hazards is used in diverse contexts and topics, showing how adaptive any definition can $\mathrm{be}^{7}$. In the area of natural hazard studies, many definitions can be found. It is clear that the many definitions related to risk are interrelated and interchangeable, and each of them has certain advantages in different applications ${ }^{8-10}$. This type of study considers risk as the product of two components, i.e. probability and consequence $^{11}$.

Flood risk means the combination of the probability of a flood event and of the potential adverse consequences ${ }^{12}$. The probability of the occurrence of potentially damaging flood events is called flood hazard ${ }^{13}$. Flood hazards include events with diverse characteristics, e.g. a structure located in the floodplain can be endangered by a 20 -year flood and water level of $0.5 \mathrm{~m}$, and by a 50 -year flood and water level of $1.2 \mathrm{~m}$. Heavy rainfall, coastal or fluvial waves, or storm surges represent the source of flood hazard. Generally these elements are characterized by the probability of flood events with a certain magnitude and other characteristics.

Different methods to assess or determine hazard, risk and vulnerability to flooding have evolved through ongoing research and practice in recent decades ${ }^{14-16}$. Deterministic and parametric modelling approaches are popular methods in deriving the flood vulnerability ${ }^{3}$. Deterministic modelling approaches, which use physically-based modelling approaches to estimate flood hazard/probability of a particular event, coupled with damage assessment models, which estimate economic consequence, and provide an assessment of flood risk in an area. Parametric approaches aim to use readily available topographic and hydrometeorological data to build a picture of the vulnerability of an area $^{2}$. Each approach has its own advantages and limitations. To help guide such policy decisions, the development of a practical method for assessing flood vulnerability is needed.

Considering the availability of spatial and non-spatial database at the national level and the ease of handling spatial database in spatial decision support system environment, parametric approach is adopted in the study. The parametric approach, introduced in the $80 \mathrm{~s}$, starts from the perspective of limited data, and has developed further since ${ }^{17}$. The parametric approach aims to estimate the complete vulnerability value of a system by using only a few readily available parameters relating to that system; however, the implementation of the approach is not simple. Different types of parametric approaches that have been developed by scientific communities are: estimating the complete vulnerability value of a system using only few parameters, estimating the imputation of nonobservable values, the parametric modelization via maximum likelihood, and the semi-parametric approach ${ }^{17}$, which allows modelling only of what is strictly necessary.

\section{Spatial and non-spatial database}

The study requires various topographic and meteorological databases (long-term) at the national level. India Meteorological Department (IMD) daily rainfall data of the country at $0.25^{\circ}$ grids for the period 1914 to 2013 (100 years) were used in rainfall analysis. Soil texture from NBSS-LUP, land-use map derived using IRS AWiFS data (NR Census: NRSC), and digital elevation model (CARTO DEM of $30 \mathrm{~m}$ resolution) were used in preparing the run-off potential of the country. Morphometric analysis was done using drainage density and topographic information of the country (data source: India WRIS). Water body (having area more than $2 \mathrm{Ha}$ ) information obtained from Bhuvan was integrated in the analysis. Approximate rail line map was obtained (source: Open Street Maps) and overlaid with the drainage map to know the possible bridge locations (first order drains were not considered in the analysis). All these databases were analysed and integrated to compute the FVI of the country in SDSS environment.

\section{Methodology framework for spatial multi-criteria decision analysis}

Preparing the FVI at the national level is a single objective and multi-criteria problem which requires integration and analysis of extensive spatial data in the SDSS environment. At the most fundamental level, a spatial multicriteria decision problem involves a set of spatially defined alternatives (events) from which a choice of one or more alternatives is made with respect to a given set of criteria $^{18}$. Spatial multi-criteria analysis is a complete transformation from the conventional multicriteria 
decision making (MCDM) techniques because of its unambiguous geographic element.

\section{The objective function}

Any decision-making process begins with the design of the decision problem. In this study, the main objective is to prepare a national FVI for assessing flood risk on Indian rail bridges, road bridges and urban infrastructure using the defined set of criteria. Once the objective function is identified or defined, the spatial multi-criteria analysis focuses on the set of evaluation criteria ${ }^{19}$. A measurement scale must be established for each variable. The degree to which objectives are met, as measured by the variables, is the basis for comparing alternatives. The evaluation criteria are associated with geographical entities and relationships between entities and therefore can be represented in the form of maps, and the criteria can be in the form of factors and constraints ${ }^{19}$.

Factors and constraints: The process of generating alternatives should be based on the value structure and related to the set of evaluation criteria. A decision variable is assigned to each alternative. Depending on the problem situation, the decision variables may be deterministic, probabilistic, or linguistic. In a real world situation, very few spatial decision problems can be considered unconstrained. Constraints represent restriction imposed on decision space and determine the set of feasible alternatives ${ }^{20}$.

India has diversified topographic, hydrological and meteorological conditions. Floods are a frequent phenomenon in the country. Indices adopted at the global scale may not be suitable at the national level to derive the FVI. A detailed and thorough study is required to identify the flood vulnerable areas in the country. Approaches and methods adopted in developing frameworks for FVI of various counties have been examined thoroughly.

With global experiences and after thorough research, different possible constraints identified for computing the FVI of the country are probable maximum precipitation (PMP), run-off potential of the country, probable maximum run-off (PMR), rainfall frequency $(>100 \mathrm{~mm})$, topographic slopes, morphometric data and water body information ( $>2 \mathrm{Ha}$ ). As the design period of rail, road, and urban infrastructure is generally 100 years, long-term hydro-meteorological data (100 years) were analysed and used in the study to compute various constraints. Programmes were written in matlab to compute the mentioned constraints in SDSS environment and the constraints are discussed below.

Probable maximum precipitation: PMP is defined as the greatest depth of precipitation meteorologically possible for a given duration in a design watershed or a given storm area at a particular location, with no allowance made for long-term climatic trends ${ }^{21}$. The objective of the PMP estimate is to calculate the PMR at a particular geographical location in a given watershed, and to further provide information that could assist in assessing the vulnerability of the location. Such a precipitation is likely to happen at a certain time of a year ${ }^{21}$. IMD daily rainfall grids of $0.25^{\circ}$ resolution for the last 100 years were used in computing PMP using statistical techniques. Maximum rainfall in each year at every pixel location was computed. PMP was computed using the maximum rainfall of each year through a statistical technique; a knowledgebased algorithm was developed in matlab to compute the PMP at each pixel location during the last 100 years as described below.

PMP during the last 100 years at pixel level was computed using the eq. (1)

$$
\mathrm{PMP}=\bar{X}_{n}+K_{m} \sigma_{n}=\bar{X}\left(1+K_{m} C_{v n}\right),
$$

where $K_{\mathrm{m}}$ is the extreme rainfall which is a statistical representation of the maximum value in the observed rainfall and computed using eq. (2)

$$
K_{\mathrm{m}}=\frac{X_{m}-\bar{X}_{n-1}}{\sigma_{n-1}},
$$

where $X_{m}$ is the maximum observed rainfall of 100 years, $\bar{X}_{n-1}$ and $\sigma_{n-1}$ are the mean and standard deviation computed excluding the extreme rainfall value respectively. $\bar{X}_{n}$ is the mean rainfall value computed from the daily rainfall data of the observed 100 years including the extreme rainfall value at each pixel. $\sigma_{n}$ and $C_{v n}$ are the standard deviation and the coefficient of variation of the precipitation series for the $n$ years of data at the design station. PMP grid that is computed using the last 100 years rainfall data is shown in the Figure 1.

Run-off potential: Run-off potential is a spatial parameter that represents the potentiality of run-off at any given pixel location and can be computed using landuse/ landcover (LULC), soil textural data and digital elevation model (DEM). Generally forest lands have less run-off potential when compared to other vegetated land use. The chance of flood hazard increases with decrease in soil infiltration capacity, which causes increase in surface run-off. Steep slopes produce more run-off than the flat terrain, since they do not allow infiltration of the rain much faster. Run-off potential map of the country was computed using the LULC map, soil textural map and digital elevation model and shown in Figure 2.

Probable maximum run-off: PMR is the maximum run-off that poses extremely serious threats to the flood control of a given project in a design watershed. Such a 
run-off could plausibly occur in a locality at a particular time of the year under current meteorological conditions ${ }^{14}$. This necessary information provides the vulnerability of a location to floods. PMR was computed using the maximum probable precipitation and run-off potential grids and shown in Figure 3. A program was written in matlab to compute the run-off at national level for each and every pixel. This grid shows the maximum run-off across the country that occurred during the last 100 years at each and every pixel location.

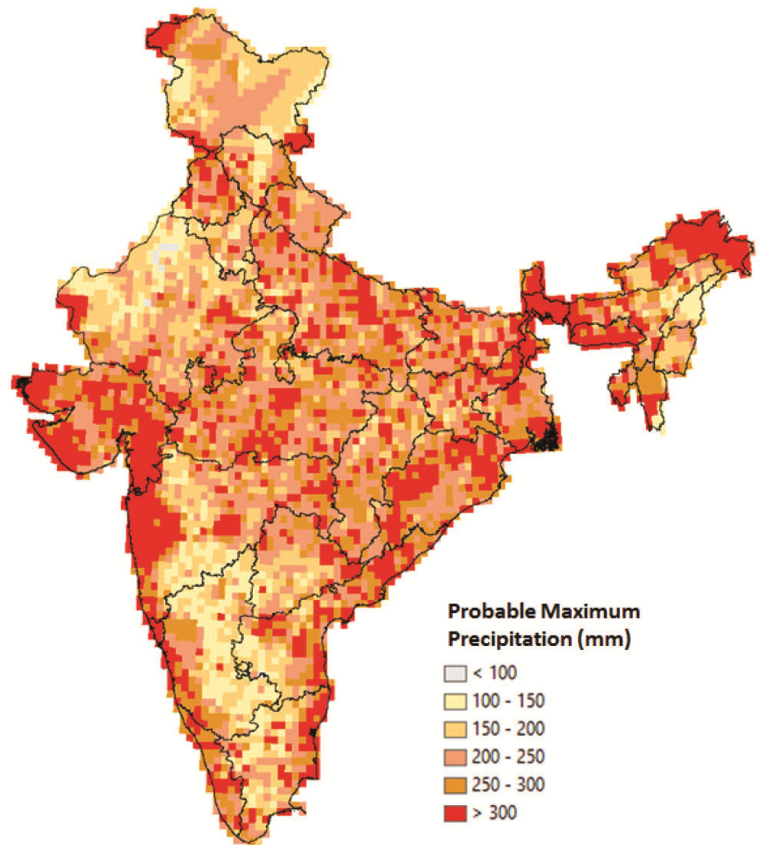

Figure 1. Probable maximum precipitation (PMP) in India (1914 to 2013).

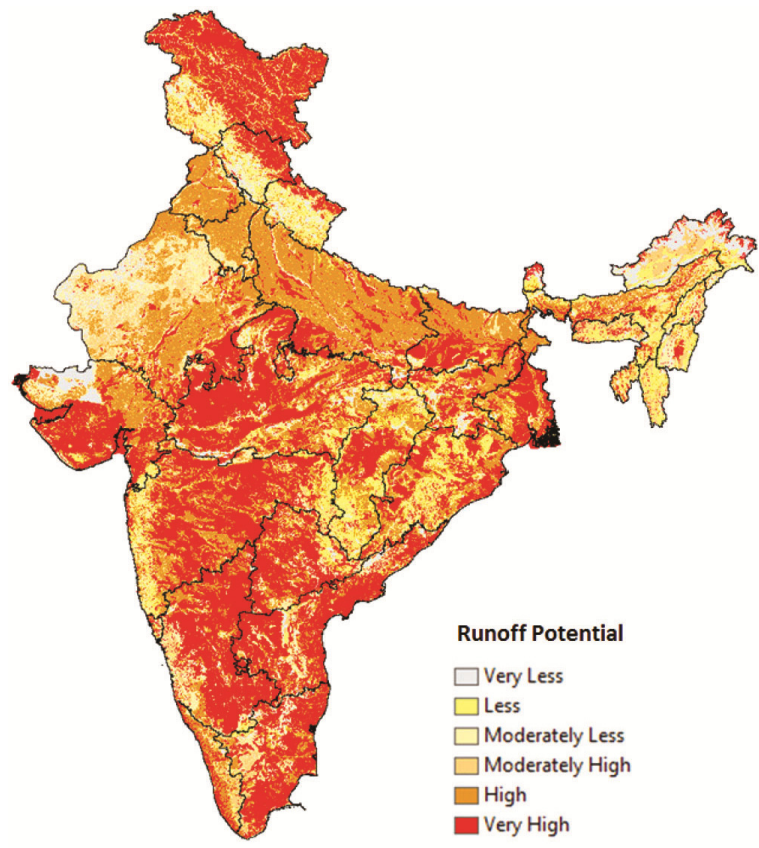

Figure 2. Run-off potential of the India.
Rainfall frequency: Rainfall frequency is defined as the number of times, during a specified period, that precipitation of a certain magnitude or greater occurs at a station. Globally it is considered that, rainfall $\geq 100 \mathrm{~mm}$ can create a flood-like situation in any area; this limit was also validated during the sensitivity analysis. IMDs daily rainfall data of the country at $0.25^{\circ}$ grids for the period 1914 to 2013 (100 years) were used in rainfall analysis. The daily rainfall data were analysed to determine the number of times rainfall in each pixel exceeded or equalled $100 \mathrm{~mm}$ during the 100 years. A knowledgebased algorithm was developed in matlab to calculate the frequency of daily rainfall and a rainfall frequency $(\geq 100 \mathrm{~mm})$ grid was computed as shown in Figure 4.

Morphometric analysis: Morphometric analysis is important in any hydrological investigation and it is inevitable in the development and management of the drainage basin $^{22}$. Morphometric analysis has been carried out using topographic and drainage maps of the country. Parameters like drainage order, bifurcation ratio, basin relief, relief ratio, drainage density and stream frequency were computed and analysed. Drainage density and type of drainage provides information related to run-off, infiltration relief and permeability. Drainage density (in terms of $\mathrm{km} / \mathrm{sq} . \mathrm{km}$ ) indicates closeness of spacing of the channel, as well as the nature of surface material, thus providing a quantitative measure of the average length of the stream channel for the whole basin. It has been observed from the drainage density measurement made over a wide range of geologic and climatic types that a low drainage

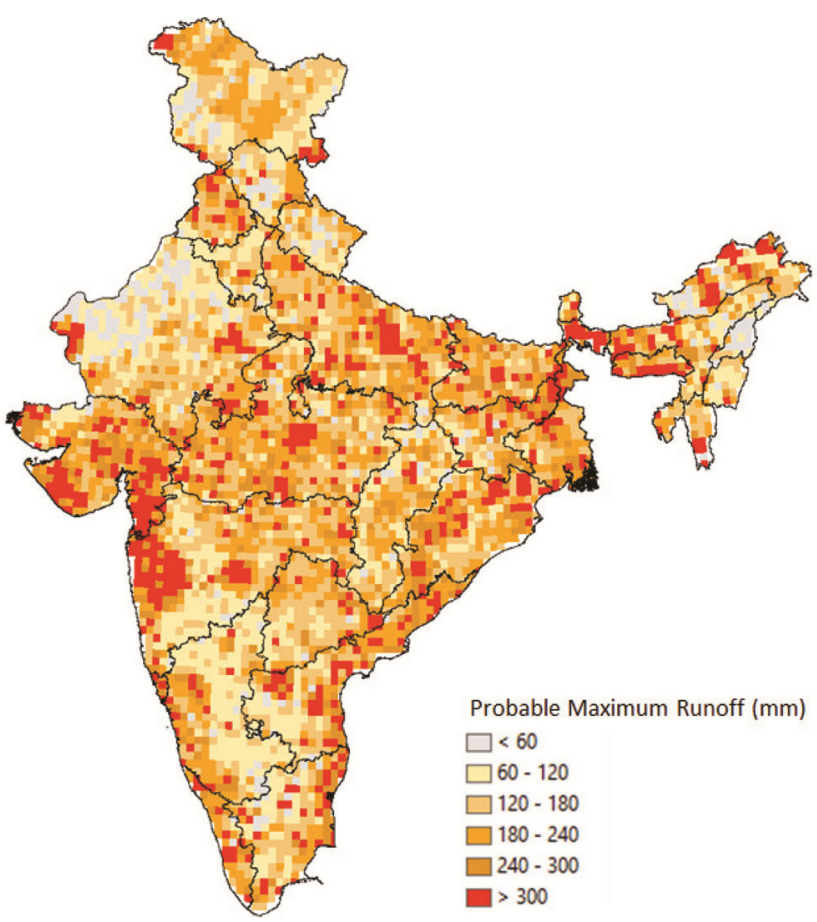

Figure 3. Probable maximum run-off (PMR) in India (1994 to 2013). 


\section{RESEARCH ARTICLES}

density is more likely to occur in the region and is highly resistant to highly permeable subsoil material under dense vegetative cover and where relief is $l_{0}{ }^{22}$. High drainage density is the resultant of weak or impermeable subsurface material, sparse vegetation and mountainous relief. The drainage density across the country was computed using the eq. (3)

$$
D_{d}=\frac{\sum_{i=1}^{n} S L_{i}}{A},
$$

where $D_{d}$ is the drainage density $(\mathrm{km} / \mathrm{sq} . \mathrm{km}), S L$ the cumulative length $(\mathrm{km})$ of all streams present within $A$ area, $A$ the area (sq. $\mathrm{km}$ ) and $n$ is the total number of streams present within the area $A$. Drainage density is computed using the drainage map of India (source: India WRIS) and is shown in Figure 5. During floods, the velocity of flow is converted into static head when the flood reaches the flat terrain; as a result it inundates more area and thus elevation and slope play an important role in deciding flood vulnerability of any area. In this study, the slope map was prepared using the CARTO $30 \mathrm{~m}$ DEM. In the slope grid, pixels having less slopes were assigned a higher rank due to almost flat terrain while the classes having maximum value were given lower rank.

\section{Decision rules}

The design phase involves inventing and analysing a set of possible solutions to the problem identified. Here, the main objective is to compute the FVI of the country using the defined criteria. At this stage, it is necessary to explore the spatial decisions criteria or the decision rules to consider to identify flood vulnerable areas. Manipulation and analysis of the data and the information stored in GIS will help in deriving spatial decisions. As the ultimate aim is to use spatial decision support system for the purpose of decision making, it is better to look into available guidelines and expert opinion at the design phase to help create rule-based decision trees or knowledge-base in expert classifier shell ${ }^{19}$.

The preferences are typically expressed in terms of weights of relative importance assigned to the evaluation criteria under consideration. The purpose of a criterion (objective and attribute) is to express the importance of each criterion relative to the other criteria. Decision rules dictate how best to rank alternatives or to decide which alternative is preferred to another. Since a decision rule provides an ordering of all alternatives according to their preference with respect to the set of evaluation criteria, the decision problem depends on the selection of the best outcome $^{20}$. In the present study, a knowledge base has been created in a hierarchical form and decision trees are used for the purpose. The analytic hierarchy approach (AHP) developed using a 9 point scale ${ }^{23}$ was used in this study as a decision-aiding method to finalize the weights assigned to different layers used in deciphering flood vulnerability. All constrains/factors were normalized between 0 and 255 linearly before assigning weightage factors to avoid the bias that exists in any constraint.

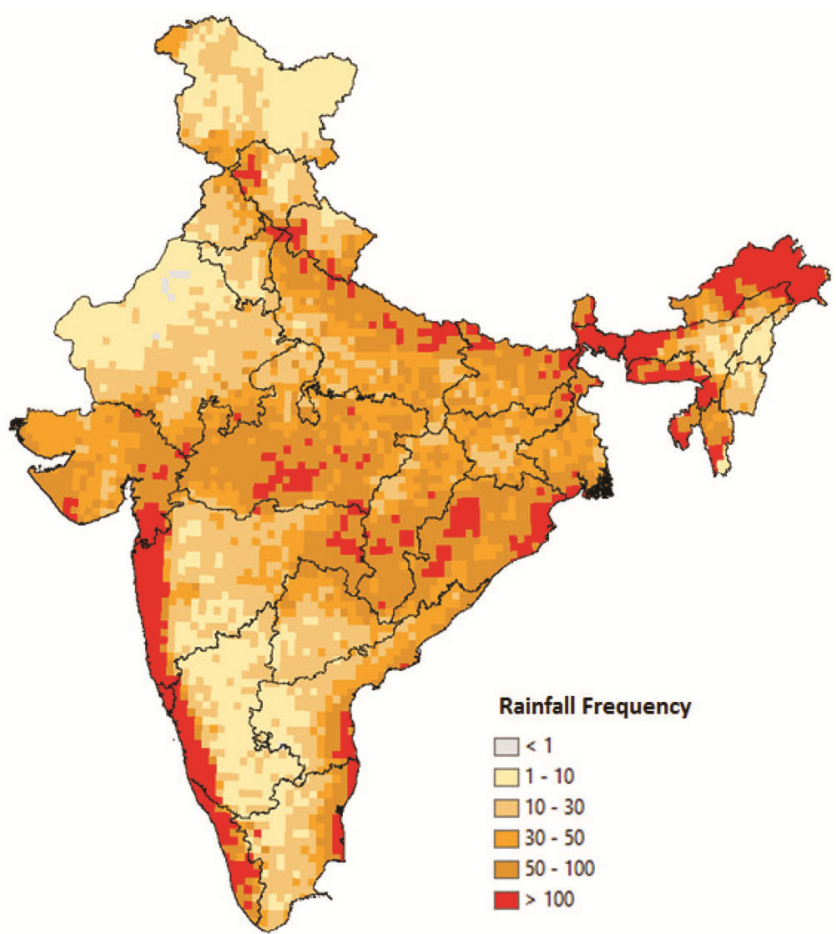

Figure 4. High rainfall frequencies $(>100 \mathrm{~mm})$ in India (1914 to 2013).

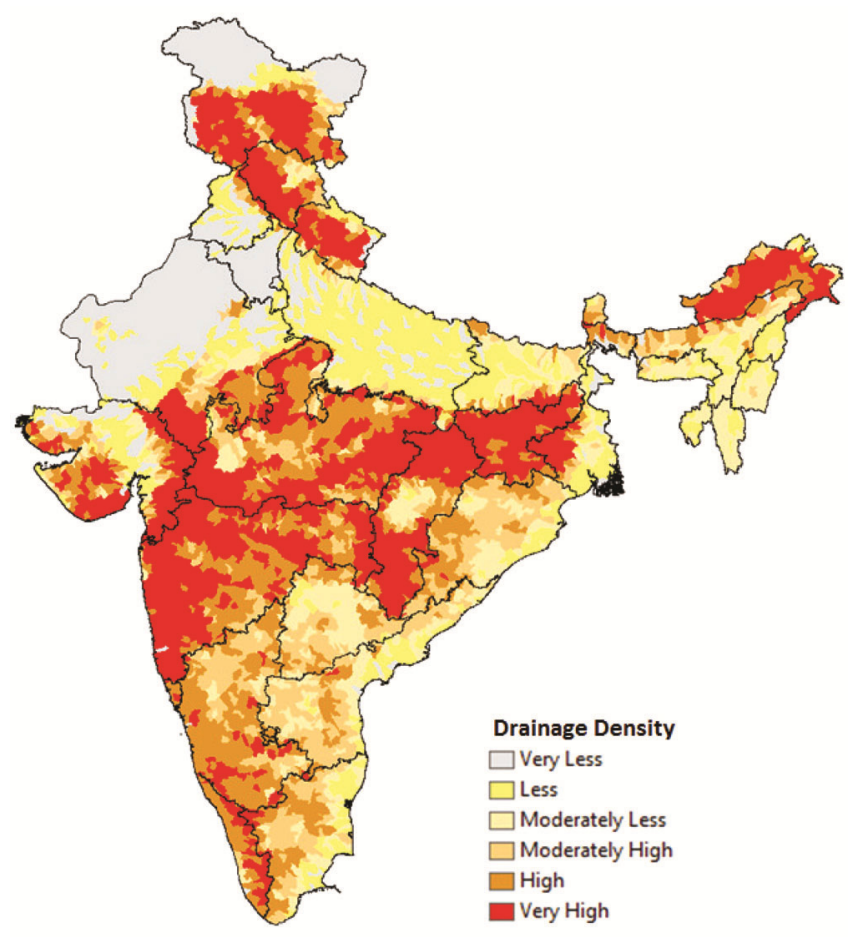

Figure 5. Drainage density of India.

CURRENT SCIENCE, VOL. 117, NO. 1, 10 JULY 2019 
The attributes of each of the layers employed in this study were assigned weightage depending on the relative contribution to flood vulnerability. The weights of the individual layers were then normalized by Saaty's AHP and the eigenvector technique was used to reduce the subjectivity associated with the assigned weights. The consistency index (CI) of the assigned weights was calculated using the eq. $(4)^{23}$. The consistency ratio (CR), which indicates the probability that the matrix ratings were randomly generated, was also computed using the values of random consistency index (RI) which is the average value of CI for random matrices using Saaty's scale.

$$
\begin{aligned}
& \text { Consistency index }=\left(\lambda_{\max }-n\right) /(n-1), \\
& \text { Consistency ratio }=\mathrm{CI} / \mathrm{RI}
\end{aligned}
$$

where $n$ is the number of criteria or factors.

It should be noted that the CR value should be less than 0.10 for consistent weights; otherwise, corresponding weights should be re-evaluated to avoid inconsistency ${ }^{23}$. Finally, all layers were integrated in SDSS environment and the FVI for the country was computed and shown in Figure 6.

\section{Sensitivity analysis}

In this kind of study, scope for change in terrain slopes, morphology, and soils with time is negligible. Probable maximum precipitation, rainfall frequency and probable maximum run-off are the main governing parameters in computing FVI. Initially it was assumed that rainfall of $100 \mathrm{~mm}$ and more can create a flood-like situation. Different rainfall threshold values were examined and

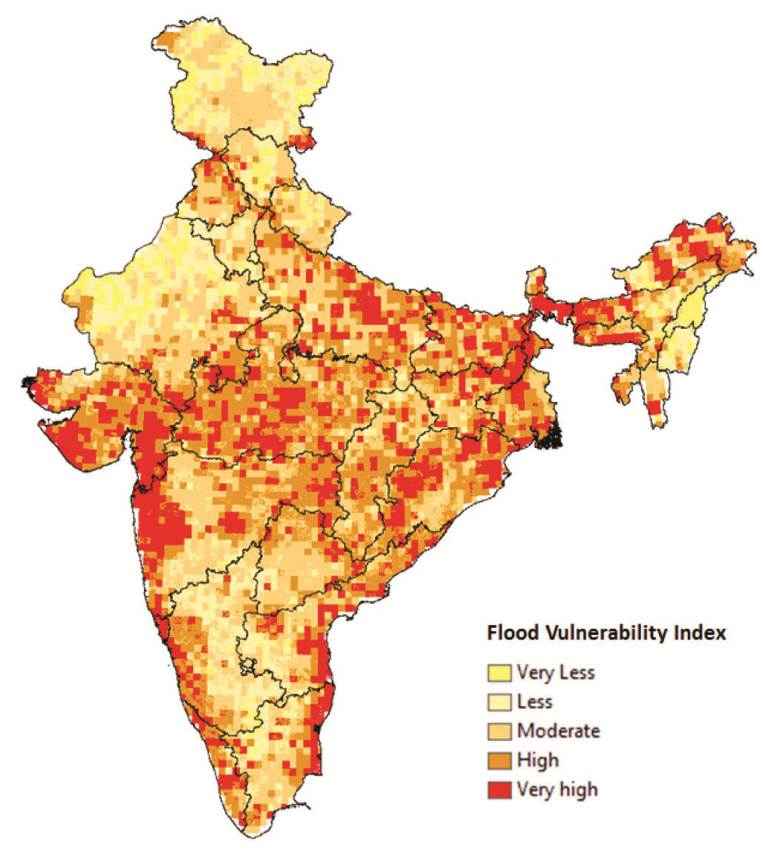

Figure 6. Flood vulnerability index of India. validated with the floodplains of the country and the historic flood events. Rainfall threshold of $100 \mathrm{~mm}$ is found to be suitable in deriving FVI of the country. Even though the weights given for different constraints are derived from the knowledge base of the best practices that are adopted across the globe, these weights were also tested for their sensitivity. Machak river floods (MP State, India) that caused collapse of the rail bridge in 2015, and the bridge collapse on Goa-Mumbai national highway due to floods in 2016 were examined and validated with the results.

\section{Results and discussions}

Data analysis of rainfall from a long period (100 years), showed that nearly $37 \%$ of the county had received rainfall of $\geq 100 \mathrm{~mm}$ for more than 50 times during the last 100 years. It is evident that SW, NE, and central part of the country received high rainfall more often. Negligible area of the country $(0.23 \%)$ had never received $\geq 100 \mathrm{~mm}$ of rainfall during the last 100 years. This analysis shows that almost all parts of the country had received rainfall of $\geq 100 \mathrm{~mm}$ once or many times during this 100 year period. More frequent, high rainfall events are highly vulnerable to flooding.

From the PMP, it can be inferred that approximately $25 \%$ of the country had received rainfall of $>300 \mathrm{~mm}$ on some or the other day during the last 100 years. Similarly nearly $47 \%$ of the area had received rainfall between 200 to $300 \mathrm{~mm}$ during this 100 -year-period at least once. It indicates that such areas are more susceptible to flooding. It is apparent that $\mathrm{SW}$ and $\mathrm{NE}$ receive highest rainfall events, and pixels having less than $100 \mathrm{~mm}$ rainfall are almost negligible. PMP in the extreme northern part of the country (J\&K states) and some parts in northeastern area of the country may not be accurate due to nonavailability of sufficient rainfall data.

The run-off potential of the country shows that the Indian terrain has more potential to generate run-off resulting from rainfall. These zones are derived based on the terrain characteristics like landuse, soils, and DEM. Maximum part of the country falls in the high to very high run-off potential zones that are more vulnerable to flooding. Very high and high run-off potential zones of the country are $34 \%$ and $30 \%$ respectively.

PMR is the function of PMP and the run-off potential. Hence, pixels having high PMP and high run-off potential are reflected as the high run-off zones. This is one of the main indicators to assess maximum possible flood situation with 100 years return period. It is interesting to note that some areas have high PMP values and moderate PMR, due to low run-off potentiality of the terrain. From the PMR, it is evident that almost every part of the country had experienced a run-off of more than $100 \mathrm{~mm}$ during the last 100 years. Very high and high PMR zones of the country are $13.5 \%$ and $10.7 \%$ respectively. 


\section{RESEARCH ARTICLES}

From the slopes across the country, it is found that maximum part of the country falls in less than 5\% slopes. Steep slopes exist in northern and north-eastern parts of the country. Flat slopes are vulnerable to riverine floods and steep slopes are exposed to flash floods. As the areal extents of steep slopes are very less, maximum attention is given to riverine floods. Drainage density in the central and southern part of India is high. It is very low in the Gujarat and Rajasthan areas. Drainage information is not available in some parts of J\&K states; hence FVI in those areas may not be accurate.

FVI of the country was computed at $1 \mathrm{~km}$ pixel resolution in the SDSS environment using the defined criteria. It is found that some parts of the western and eastern coast, parts of northeast, central India, and Gangetic plains are highly vulnerable. Nearly $19 \%$ and $28 \%$ of the Indian territory are very highly and highly vulnerable to flooding respectively. FVI in the extreme northern part of the country (J\&K states) and some parts in northeastern area of the country may not be accurate due to nonavailability of sufficient rainfall data.

The FVI map of the country is computed based on the long-term meteorological data and high resolution topographic data; it may not depict the floodplain zones of the country as it also depends on the upstream catchment conditions. FVI is calculated based on long-term rainfall data (100 years) and topographic data keeping in view the life-span of rail, road and urban civil infrastructure. Flood vulnerability of rail and road bridges and urban infrastructure mainly depends upon resilience such as structural stability, age of construction, maintenance, etc. FVI is calculated using long-term historical rainfall data at $0.25^{\circ}$ resolution obtained from IMD. It may not represent the effect of localized thunderstorms and its flash floods, and the impact due to cyclonic floods and sea wave flooding.

1. WMO, Associated program on flood management. Technical Support Unit, Associated Programme on Flood Management Technical Document No. 1, 2004, 2nd edn.

2. Yashon, O. O. and Ryutaro, T., Urban flood vulnerability and risk mapping using integrated multi-parametric AHP and GIS: methodological overview and case study assessment. Water, 2014, 6, 1515-1545; doi:10.3390/w6061515.

3. Balica, S. F., Wright, N. G. and vander Meulen, F., A flood vulnerability index for coastal cities and its use in assessing climate change impacts. Nat. Hazards, 2012, 64(1), 73-105; doi:10.1007/s11069-012-0234-1.

4. Balica, S. F., Popescu, I., Beevers, L. and Wright, N. G., Parametric and physically based modeling techniques for flood risk and vulnerability assessment: a comparison. Environ. Model. Softw. 2013, 41, 84-92; doi:10.1016/j.envsoft.2012.11.002.

5. Mikhail, C., Andrew, F. and Matthew, B., Frameworks for assessing the vulnerability of US rail system to flooding and extreme heat. Arizona State University, Report no. ASU-SSEBE-CESEM2015-RPR-001, 2015.

6. Kong, D., Setunge, S., Molyneaux, T., Zhang, G. and Law, D., Structural resilience of core port infrastructure in a changing climate, enhancing the resilience of seaports to a changing climate report series, National Climate Change Adaptation Research
Facility, Gold Coast, 2013; ISBN: 978-1-921609-86-2 NCCARF Publication 15/3.

7. Sayers, P., Hall, J., Dawson, R., Rosu, C., Chatterton, J. and Deakin, R., Risk assessment of flood and coastal defenses for strategic planning (RASP) - a high level methodology. Wallingford, 2002; http://www.raspproject.net/RASP_defra2002_Paper_Final.pdf

8. Plate, E. J., Flood risk and flood management. J. Hydrol., 2002, 267, 2-11.

9. Barredo, J. I., de Roo, A. and Lavalle, C., Flood risk mapping at European scale. Water Sci. Technol., 2007, 56(4), 11-17.

10. Merz, B., Thieken, A. H. and Gocht, M., Flood risk mapping at the local scale: concepts and challenges. In Flood Risk Management in Europe 25. Advances in Natural and Technological Hazards Research (eds Begum, S., Stive, M. J. F. and Hall, J. W.), Springer, The Netherlands, 2007, pp. 231-251.

11. Smith, K., Environmental Hazards: Assessing Risk and Reducing Disaster, Routledge, London, 2004, e book; ISBN 9780203595015 .

12. UNEP, Manual: How to Use the Environmental Vulnerability Index (EVI), 2004; http://www.vulnerabilityindex.net/EVI Calculator.htm

13. Schanze, J., Flood risk management - a basic framework. Flood Risk Management: Hazards, Vulnerability and Mitigation Measures, NATO Science Series: IV: Earth and Environmental Sciences, 2006, 67(Part 1), 1-20.

14. Xia, J., Falconer, R. A., Lin, B. and Tan, G., Numerical assessment of flood hazard risk to people and vehicles in flash floods. Environ. Modell. Softw., 2011, 26(8), 987-998.

15. Hartanto, I. M., Beevers, L., Popescu, I. and Wright, N. G., Application of a coastal modeling code in fluvial environments. J. Environ. Model. Softw., 2011, 26(12), 1685-1695.

16. Gichamo, Z., Popescu, G., Jonoski, I. A. and Solomatine, D. P., River cross section extraction from ASTER global DEM for flood modeling. J. Environ. Model. Softw., 2012, 31(5), 37-46.

17. Little, R. J. A. and Rubin, D. B., Statistical Analysis with Missing Data, J. Wiley and Sons, New York, 1987.

18. Simon, H. A., The New Science of Management Decision, Harper and Row, New York, 1960.

19. Durga Rao, K. H. V., Multicriteria spatial analysis for forecasting urban water requirements - a case study of Dehradun City, India. Int. J. Landscape Urban Planning, 2005, 71(2-4), 163-174.

20. Durga Rao, K. H. V. and Bhaumik, M. K., Spatial expert support system in locating suitable sites for water harvesting structures - a case study of song watershed in Dehradun. Int. J. Geocarto., 2003, 18(4), 43-51.

21. WMO, Manual on estimation of probable maximum precipitation, WMO-No. 1045, 2009; http://www.wmo.int/pages/prog/hwrp/ publications/PMP/WMO\%201045\%20en.pdf

22. Clarke, J. I., Morphometry from Maps. Essays in Geomorphology, Elsevier Publications, New York, 1996, pp. 235-274.

23. Saaty, T. L., The Analytic Hierarchy Process, McGraw-Hill, New York; International: RWS Publications, Pittsburgh, 1980.

ACKNOWLEDGEMENTS. We acknowledge the support and guidance provided by Sri Santanu Chowdury, Director, NRSC, Dr P. G. Diwakar, Director, EDPO, ISRO, Dr V. Bhanumurthy, Associate Director, NRSC and Dr P. V. N. Rao, Deputy Director, Remote Sensing Applications, NRSC. Support and guidance provided by Dr Y. V. N. Krishna Murthy, former Director, NRSC and Dr V. V. Rao, GD-WRG, NRSC are acknowledged.

Received 2 November 2018; revised accepted 8 April 2019

doi: $10.18520 / \mathrm{cs} / \mathrm{v} 117 / \mathrm{i} 1 / 80-86$ 